\title{
Amputation of Foot
}

National Cancer Institute

\section{Source}

National Cancer Institute. Amputation of Foot. NCI Thesaurus. Code C51937.

The surgical removal of all or part of the foot. 